\title{
Investigations of the regularity of the formation of a dip over the mine
}

\author{
Peter Dolzhikov ${ }^{1}$, Albert Prokopov ${ }^{1, *}$, Marina Prokopova $^{2}$, and Natalya Hamidullina ${ }^{2}$ \\ ${ }^{1}$ Don state technical University, 344000, Rostov-on-Don, Gagarin square, 1, Russia \\ ${ }^{2}$ Rostov State Transport University, 344038, Rostov-on-Don, Rostovskogo Strelkovogo Polka \\ Narodnogo Opolcheniya square, 2, Russia
}

\begin{abstract}
The article presents the results of physical simulation of the formation of a dip over the mine workings. For this purpose, similarity criteria are substantiated and an experimental stand is developed. On samples of quaternary loam and clay it is proved that the velocity of the motion of the dip depends nonlinearly on the moisture content and exponentially damps in time.
\end{abstract}

\section{Introduction}

Full-scale studies in closed coal mines have shown that with intensive deformations of the laying material, a loss of stability of the near-barreled sandy-argillaceous mass occurs and the formation of a dip [1-8]. At the same time, the mechanism, geometric parameters and the formation time of failures are reliably determined. However, in situ studies it is very difficult to establish the regularity of the formation of a dip, almost always a failure was recorded as a fact of the completed engineering-geological process. Therefore, it is very expedient to study the regularity of the formation of a dip through determining factors and characteristics by the method of physical modeling [9].

The aim of the research is to establish the patterns of deformation of sandy-argillaceous rocks in the zone of failure.

\section{Methodology}

In the study of disastrous facts, mathematical and physical modeling is applied with an attempt to comply with the energy and dynamic, geometric and other similarity criteria. However, it should be recognized that it is very difficult to fully comply with the requirements of the similarity theory, and therefore they limit themselves to studying, as a rule, only the main characteristics of the phenomenon, neglecting the minor details [9].

The study of all these questions by the analytical method and directly in practice is connected with great difficulties, therefore the use of the modeling method has great theoretical and practical importance. The best way to achieve our goals is a modeling method using real rocks.

\footnotetext{
* Corresponding author: prokopov72@rambler.ru
} 
To carry out experiments, it is necessary to establish similarity criteria and select model parameters. In order for the process in the model to be similar to a process in nature, it is necessary and sufficient to fulfill the following requirements:

- The model should be geometrically similar to the sample;

- processes in the model and sample must belong to the same class and be described by the same differential equations;

- initial and boundary conditions in the model must be realized in such a way that the dimensionless initial and boundary conditions of the model coincide identically with the same conditions in nature;

- the dimensionless parameters of the same name that enter the differential equations, the initial and boundary conditions, and in the model and in nature, the conditions must be respectively equal.

The most convenient method of physical modeling, allowing to reproduce mechanical processes of deformation and destruction of rocks on the model, is the proposed $\pi$-theorem published by Buckingham in 1917.

To determine the independent physical quantities, let us consider the process of formation of a dip in the earth's surface above the mine workings.

In modeling, we will assume that the main process to be studied is deformation of sediment rocks, which is characterized by the following parameters: $\gamma$ - specific gravity; $e-$ void ratio of the material; $a$ - compression ratio; $E$ - modulus of deformation; $W$ - moisture content; $h$-depth of the dip.

To compose the function of the deformation process of the sediments, we select from the listed quantities the most important, that is, the prevailing action. We write the following function of the deformation process:

$$
\Delta h_{i}=f\left(t, q_{c}, W, E, h, d\right)
$$

where $\Delta h_{i}-$ absolute deformation of the sediment at time $t_{\mathrm{i}} ; t$-deformation time; $q$ - total weight of sediment in the zone of failure.

The recorded function includes 6 parameters, since at a given stage of the study moisture is excluded as a dimensionless quantity.

We apply the $\pi$-theorem to construct the similarity criteria for the process under study. The number of such criteria is $N-k=3$.

As independent variables we choose: the time $t$, the characteristic diameter of the $\operatorname{dip} d$, the deformation modulus of the rocks $E$. Consequently, according to the $\pi$-theorem, the similarity criteria for the deformation process have the form:

$$
\pi_{1}=\frac{d}{h}, \quad \pi_{2}=\frac{d}{\Delta h}, \quad \pi_{3}=\frac{E d^{2}}{q_{c}} .
$$

It is seen that the first criterion of similarity characterizes the geometric similarity, the second - kinematic, the third - the deformation.

Thus, we obtained a criterial function in the form:

$$
\Phi\left(\frac{d}{h} ; \frac{t \cdot v}{d W} ; \frac{E \cdot d^{2}}{q_{c}}\right)=0 .
$$

Let us analyze the obtained criteria. From the first criterion follows the necessity of observing geometrical similarity. 
Proceeding from the fact that the lower diameter of the dip often corresponds to 3-5 $\mathrm{m}$, and the depth - the thickness of the sediment, we find the coefficient of geometric similarity:

$$
C_{d}=\frac{d_{n}}{d_{m}}=\frac{h_{n}}{h_{m}}=\frac{1000}{10}=100 .
$$

Modeling will be performed under the condition that $W_{m}=W_{n}$. Hence the need to observe kinematic similarity:

$$
t_{n} \cdot V_{n}=100 \cdot t_{\mathrm{m}} \cdot v_{\mathrm{m}}
$$

that is, $\Delta h_{n}=100 \cdot \Delta h_{m}$, and the rock strain rate on the model is decelerated 10 times under the condition $t_{n}=10 \cdot t_{m}$.

Thus, when modeling the process of the failure of the earth's surface over the mine workings, we take into account the time, the characteristic diameter of the dip, and the strain rate of the rocks. All other factors (energy and power) are just a combination of the above parameters in a different combination.

When carrying out laboratory experiments on modeling the process of formation of a dip, the information parameters are the time, velocity and sedimentation of rocks. It is these indicators that properly characterize the development of the failure.

The physical model of a dip over the mine workings consists of a funnel wrapped with sandpaper, with an angle of $65^{\circ}$. The bottom outlet of the funnel had a diameter of $5 \mathrm{~cm}$. Closing the latter, a sandy-clay rock was loaded into the funnel. Having established the indicators of the watch type, the lower opening was opened and further the process of rock deformation was controlled due to the developing shearing and compressive stresses. Given the geometric parameters of the funnel of the failure, density and moisture of rocks, the main control parameters were absolute deformation $\Delta h$ and time $t$. This allowed us to study the regularity of the development of the failure process. In this case, the condition $\sigma_{\mathrm{m}}=\sigma_{\mathrm{n}}$ was observed.

In physical modeling, Quaternary brown clays and loams were used as full-scale rock samples. Their engineering and geological properties are given in Table 1.

Table 1. Geotechnical properties of rocks.

\begin{tabular}{|c|c|c|c|c|c|c|c|}
\hline Soils & $\begin{array}{c}\text { Density } \\
\times 10^{3} \mathrm{~kg} / \mathrm{m}^{3}\end{array}$ & $\begin{array}{c}\text { Water } \\
\text { content, } \%\end{array}$ & $\begin{array}{c}\text { Void, } \\
\%\end{array}$ & $\begin{array}{c}\text { Plasticity } \\
\text { index }\end{array}$ & $\begin{array}{c}\text { Specific } \\
\text { adhesion, } \\
\mathrm{MPa}\end{array}$ & $\begin{array}{c}\text { Angle of } \\
\text { internal } \\
\text { friction, }\end{array}$ & $\begin{array}{c}\text { Coefficient } \\
\text { of filtration, } \\
\mathrm{m} / \mathrm{s}\end{array}$ \\
\hline Loam & 1.80 & 22 & 40 & 15 & 0.026 & 23 & $2.3 \cdot 10^{-7}$ \\
\hline Clay & 2.05 & 24 & 56 & 26 & 0.040 & 18 & $4.2 \cdot 10^{-8}$ \\
\hline
\end{tabular}

During the experimental studies, the moisture content of the clay rocks varied within the limits of the plastic consistency. Measurements of the absolute deformation of life are performed after twelve hours with an accuracy of $0.01 \mathrm{~mm}$ at three points. The average result was recorded in the research journal. The speed of the deformation process was calculated from the obtained data.

\section{Results}

Based on the results of physical modeling of dips on loam and clay samples, graphical dependences of the deformation rate of rocks on time and humidity in the interval of plastic consistency were obtained (Figures 1 and 2). The analysis of the obtained dependences by 
the method of correlation-regression analysis made it possible to conclude that the rate of deformation of the sediment rocks during the formation of the dips decreases exponentially.

Correlation-regression analysis also revealed a close relationship between the rate of formation of a dip and the moisture content of sediment rocks $\left(R^{2}=0.97-0.98\right)$, and also determine the type and parameters of their dependence. The best was a polynomial dependence of the form:

- for loam

- for clay

$$
\begin{aligned}
& v=0.075 W^{2}-3.67 W+53.6 \\
& v=0.031 W^{2}-1,96 W+38.7
\end{aligned}
$$

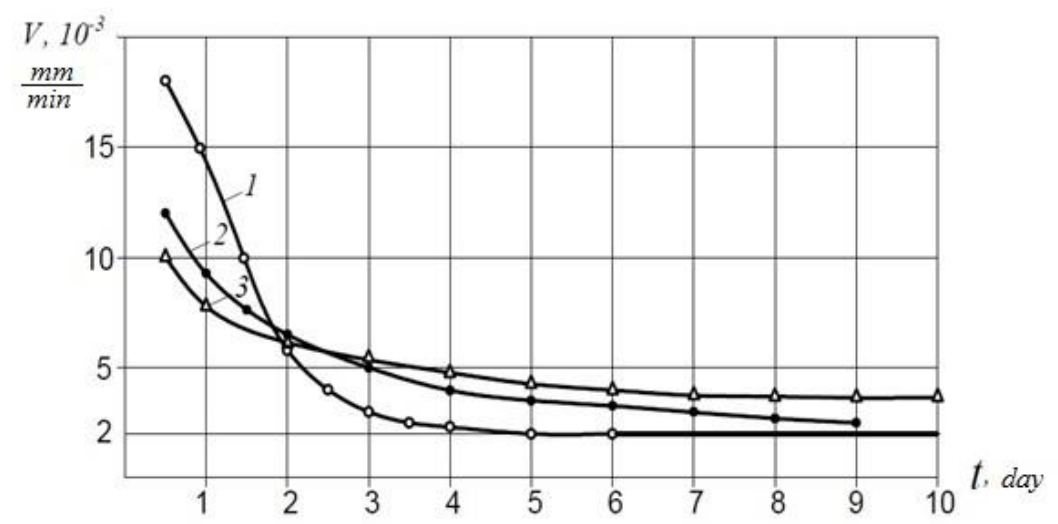

Fig. 1. Dependence of the rate of deformation of loam on time on the failure model: $1-W=36 \% ; 2-W=30 \% ; 3-W=23 \%$

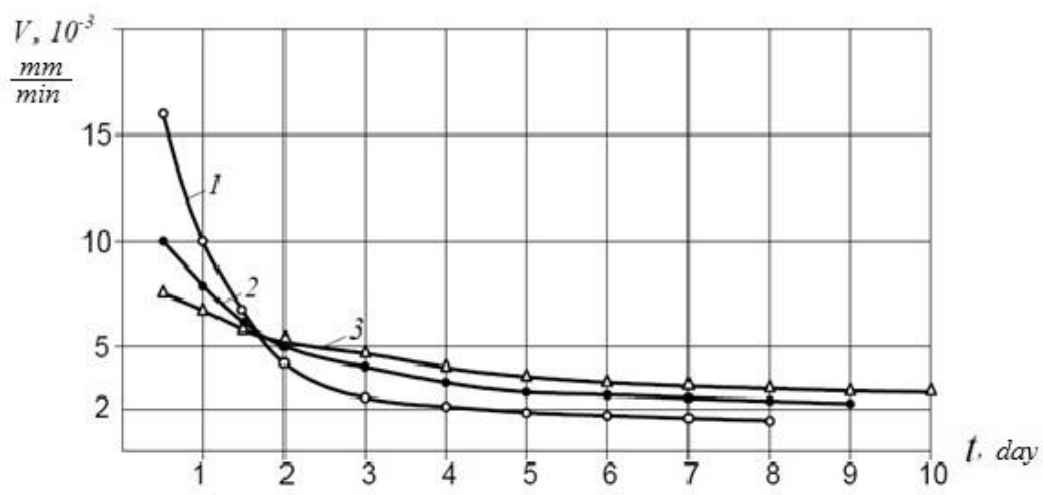

Fig. 2. Dependence of the clay deformation rate on time on the failure model: $1-W=48 \% ; 2-W=40 \% ; 3-W=30 \%$ :

Thus, the obtained dependences (Figures 1 and 2) are described by the expression:

$$
v(t)=A(W) e^{-\beta t},
$$


where $A(W)$ - empirical parameter characterizing the primary deformation rate as a function of the moisture content of the rocks; $\beta$ - empirical exponent of the decay of the formation of the dip.

\section{Analysis}

Let us write the law of deformation of rocks in a linear form:

$$
\ln v(t)=\ln A(W)-\beta t
$$

Graphically, the change in the logarithmic rate of deformation of loam and clay in time is shown in Figures 3 and 4.

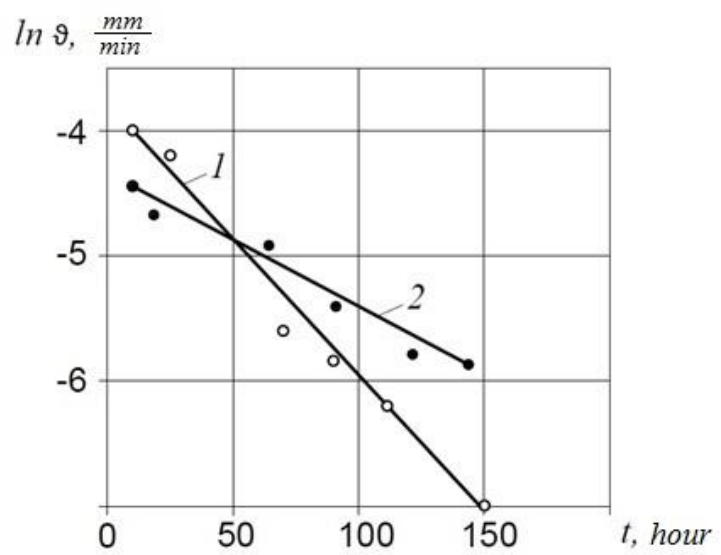

Fig. 3. Change in the logarithmic rate of deformation of loam in time: $1-W=36 \% ; 2-W=30 \%$

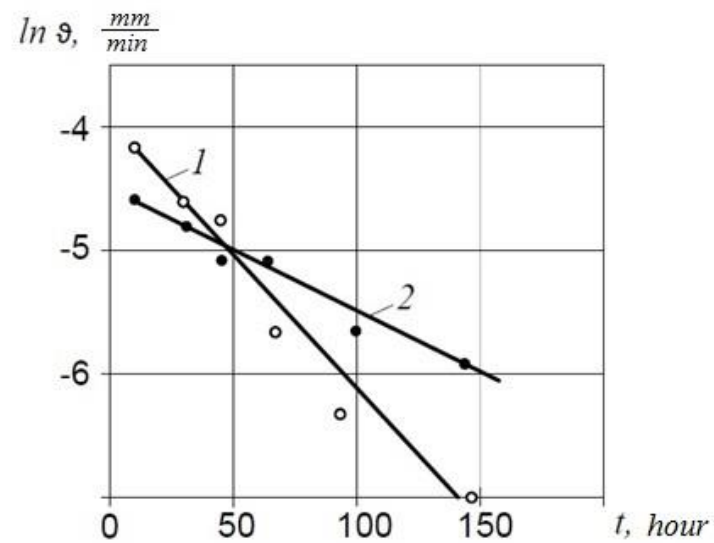

Fig. 4. The change in the logarithmic rate of clay deformation in time: $1-W=48 \% ; 2-W=40 \%$

It is seen that the decay rate of the deformation rate is defined as the tangent of the slope of the lines obtained: 


$$
\beta=\frac{\ln A(W)-\ln v(t)}{t_{1}-t}=\operatorname{tg} \alpha .
$$

where $t_{1}$ - primary recording time for the rock failure rate; $t$ - main time of formation of the dip.

The processing of the simulation results allowed to determine the empirical parameters in the exponential pattern of the deformation rate of the dip, which are given in Table 2.

Table 2. Empirical parameters in the regularity of the rate of strain deformation

\begin{tabular}{|c|c|c|c|c|}
\hline Soils & Water content, $\%$ & $A, 10^{-3} \mathrm{~mm} / \mathrm{min}$ & $\beta, \mathrm{h}^{-1}$ & $R^{2}$ \\
\hline \multirow{2}{*}{ Loam } & 36 & 22.8 & 0.022 & 0.90 \\
\cline { 2 - 5 } & 30 & 13.0 & 0.011 & 0.88 \\
\hline \multirow{2}{*}{ Clay } & 48 & 19.3 & 0.022 & 0.87 \\
\cline { 2 - 5 } & 40 & 11.1 & 0.010 & 0.92 \\
\hline
\end{tabular}

\section{Discussion}

It follows from the table that the determination coefficients for the dependences obtained are $0.87-0.92$, which satisfy the accuracy of the studies.

Thus, by physically simulating the formation of a dip over a rock formation on Quaternary loam and clay samples, the exponential dependence of the deformation rate of rocks on time and the polynomial dependence on humidity are established. These dependencies form the basis for the development of a combined method for eliminating a failure over production.

\section{References}

1. E. Kipko, P. Dolzhikov, V. Ryabichev, Integrated technology for the elimination of inclined mine workings of closed mines (Nord-press, Donetsk, 2005)

2. E. Kipko, P. Dolzhikov, N. Dudla, Complex method of plugging in the construction of mines (NMU, Dnipropetrovsk, 2004)

3. A. Vorobiev, A. Prokopov, G. Lotsev, Experience and prospects of restructuring and development of the coal industry in the countries of the European Union and the CIS (Lik, Novocherkassk, 2011)

4. A. Prokopov, V. Golik, S. Maslennikov, Scientific Review, 9-3, 726-729 (2014)

5. V. Driban, A. Feofanov, S. Goldin, Scientific works UkrNIMI, 7, 14-21 (2010)

6. A. Belodedov, P. Dolzhikov, S. Legostaev, Izvestiya of TSU. Sciences about the Earth, 1, 160-169 (2017)

7. A. Prokopov, V. Zhur, Y. Rubtsova, Sergeevskie read. Engineering geology and geoecology, 18, 346-351 (2016)

8. M. Prokopova, G. Lukyanova, Construction (RGSU, Rostov-on-Don, 2011)

9. I. Nasonov, V. Resin, Modeling of physical processes in mining (AGN, Moscow, 1999) 